\title{
Direct convective delivery of adeno-associated virus gene therapy for treatment of neurological disorders
}

\author{
Russell R. Lonser, MD, ${ }^{1}$ Asad S. Akhter, MD, ${ }^{1}$ Mirosław Zabek, MD, PhD, ${ }^{2}$ J. Bradley Elder, MD, ${ }^{1}$ \\ and Krystof S. Bankiewicz, MD, PhD' 1
}

\begin{abstract}
${ }^{1}$ Department of Neurological Surgery, The Ohio State University Wexner Medical Center, Columbus, Ohio; and 2Department of Neurological Surgery, Bródno Hospital, Warsaw, Poland
\end{abstract}

\begin{abstract}
Molecular biological insights have led to a fundamental understanding of the underlying genomic mechanisms of nervous system disease. These findings have resulted in the identification of therapeutic genes that can be packaged in viral capsids for the treatment of a variety of neurological conditions, including neurodegenerative, metabolic, and enzyme deficiency disorders. Recent data have demonstrated that gene-carrying viral vectors (most often adeno-associated viruses) can be effectively distributed by convection-enhanced delivery (CED) in a safe, reliable, targeted, and homogeneous manner across the blood-brain barrier. Critically, these vectors can be monitored using real-time MRI of a co-infused surrogate tracer to accurately predict vector distribution and transgene expression at the perfused site. The unique properties of CED of adeno-associated virus vectors allow for cell-specific transgene manipulation of the infused anatomical site and/or widespread interconnected sites via antero- and/or retrograde transport. The authors review the convective properties of viral vectors, associated technology, and clinical applications.
\end{abstract}

https://thejns.org/doi/abs/10.3171/2020.4.JNS20701

KEYWORDS adeno-associated virus; convection-enhanced delivery; gene therapy; neurological disorder; treatment; oncology

$\mathrm{C}$ ONVECTION-ENHANCED delivery (CED) allows for the safe, homogeneous, reliable, and targeted perfusion of CNS structures with putative therapeutics, including viral vectors, across the blood-brain barrier (BBB) ${ }^{1-3}$ Specifically, new insights into the biological properties of adeno-associated virus (AAV) vectors for transgene expression after direct nervous system delivery provide new therapeutic opportunities for the treatment of neurological disorders that are ineffectively treated or untreatable. Unique AAV properties are being exploited to perfuse targeted cell-specific deep brain structures and interconnected regions (via antero- and/or retrograde transport) for the sustained transgene expression of putative therapeutics to treat diseased nervous system structures and circuits. ${ }^{4-12}$ Convective perfusion of targeted structures with an AAV can be monitored using a surrogate MRI tracer to define vector distribution and predict transgene expression at the site of perfusion..$^{13-15}$ Emerging translational and clinical findings, using direct convective delivery and image monitoring, have demonstrated that targeted AAV gene therapy can be used to successfully treat neurodegenerative, metabolic, and enzyme deficiency disorders. We review the features, techniques, and disorders treated using direct intraparenchymal convective AAV gene therapy.

\section{Nervous System Gene Therapy AAV Biology}

Currently, the use of therapeutic DNA or RNA in gene therapy requires a viral vector for effective cellular uptake and translation in targeted nervous system cells. ${ }^{16-18} \mathrm{AAV}$ is the most commonly used vector for CNS gene therapy. AAV is a small $(25 \mathrm{~nm})$, nonreplicative, nonpathogenic, nonenveloped parvovirus that attaches to cells primarily through heparin-sulfate proteoglycan receptors and is then internalized by endocytosis. After endocytosis, AAV is trafficked to the cell nucleus where it is uncoated and the vector genome is released. Once inside the host cell nucleus, the AAV vector genome forms a lasting extrachromo-

ABBREVIATIONS AADC = aromatic L-amino acid decarboxylase; $\mathrm{AAV}=$ adeno-associated virus; $\mathrm{BBB}=$ blood-brain barrier; $\mathrm{CED}=$ convection-enhanced delivery; $\mathrm{GAD}=$ glutamic acid decarboxylase; GDNF = glial cell-derived neurotrophic factor; PD = Parkinson's disease; STN = subthalamic nucleus.

SUBMITTED March 5, 2020. ACCEPTED April 16, 2020.

INCLUDE WHEN CITING Published online July 10, 2020; DOI: 10.3171/2020.4.JNS20701. 
TABLE 1. Viral vector characteristics

\begin{tabular}{|c|c|c|c|c|c|c|}
\hline Viral Vector & Intravenous & Intramuscular & CSF & Parenchymal & Cellular Trophism & Transport \\
\hline \multicolumn{7}{|l|}{ AAV } \\
\hline Serotype 1 & & $x$ & & & $\mathrm{~N}, \mathrm{~A}, \mathrm{NN}$ & ret, ant \\
\hline Serotype 2 & & $x$ & & $x$ & $\mathrm{~N}$ & ant \\
\hline Serotype 2/6 & $X$ & & & & $\mathrm{~N}, \mathrm{~A}$ & \\
\hline Serotype 5 & & & & $x$ & $\mathrm{~N}, \mathrm{~A}, \mathrm{NN}$ & ret, ant \\
\hline Serotype 6 & $x$ & $x$ & & & $\mathrm{~N}, \mathrm{~A}$ & ret \\
\hline Serotype 8 & $x$ & & & & $\mathrm{~N}, \mathrm{~A}, \mathrm{NN}$ & ret, ant \\
\hline Serotype 9 & $x$ & & $x$ & $x$ & $N, A, N N$ & ret, ant \\
\hline Serotype rh74 & $X$ & $X$ & & & & \\
\hline Serotype rh10 & & & & $x$ & $\mathrm{~N}, \mathrm{~A}, \mathrm{NN}$ & ant \\
\hline Lentivirus & $x$ & & & $x$ & A & ret \\
\hline Moloney leukemia virus & & & & $x$ & $\mathrm{~N}$ & \\
\hline Herpes simplex $1^{*}$ & $x$ & & & $x$ & $N, G, N N$ & ret, ant \\
\hline
\end{tabular}

somal episome (and/or, in rare cases, integrates into the host genome at chromosome 19), facilitating persistent host cell transgene expression.

\section{Routes of Delivery}

The route of delivery of viral vectors for gene therapy is dictated by the anatomical target and vector distribution characteristics. Specifically, available CNS delivery methods for gene therapy include intravenous, intramuscular, $\mathrm{CSF}$, and direct intraparenchymal routes. Intravenous delivery of viral vectors is limited by the BBB (except for isolated AAV serotypes) and nontargeted systemic/ nervous system distribution (Table 1). ${ }^{5,7,19,20}$ Intramuscular delivery of viral vectors has been used to treat spinal cord targets (often in motor neuron disease) by retrograde transport of the vector from the muscle to the spinal cord. This form of delivery can be limited by axonal dysfunction and restricted regional vector spread. CSF delivery can be exploited to provide widespread CNS distribution while minimizing systemic exposure. However, tight ependymal cell junctions prevent most viral vectors from effectively penetrating into nervous system tissue.

While direct intraparenchymal convective delivery of viral vectors requires a neurosurgical procedure, there are a number of critical advantages to this method of vector distribution. First, direct delivery of viral vectors permits cell or region-specific targeted distribution of gene therapy and can reduce off-target effects. Critical sites of diseased neuronal circuitry can be directly treated, while avoiding normal nervous system tissues. Second, because the brain is an immune-privileged site, direct delivery of viral vectors can avoid or reduce the impact of preexisting humoral immunity that can limit the use or transduction efficiency for systemic applications. Third, the use of different viral capsids permits the antero- and/or retrograde transduction for the treatment of interconnected diseased neuronal circuits when broader (circuit-wide) therapeutic effects are need. Finally, the use of co-infused surrogate tracers allows for the real-time monitoring and control of viral vector (and definition of perfusion site transduction) perfusion at the delivery.

\section{Current Trials}

The number of gene therapy trials for the treatment of CNS disease has increased dramatically in the last few years. Currently, there are 68 gene therapy trials for CNS disorders (excluding eye and tumors) in the US National Library of Medicine database (ClinicalTrials.gov; Table 2) that have US Food and Drug Administration Center for Biologics Evaluation and Research approval (approval process for gene therapy can be found at https://www.fda. gov/about-fda/center-biologics-evaluation-and-researchcber/about-cber). The route of administration and viral vector used is determined by the anatomical target, as well as vector transport and cellular trophism. The most frequent routes of administration for viral vectors include direct intraparenchymal 44\%), intravenous (35\%), and intramuscular (13\%) (Fig. 1). The most common viral vector used for CNS gene therapy is AAV (88\% of all viral vectors used in active clinical trials; Fig. 1). The most common AAV serotypes used in CNS gene therapy trials (all routes of delivery) include AAV2 (33\%) and AAV9 (27\%) (Fig. 2). Specifically, AAV is used in $90 \%$ of direct intraparenchymal gene therapy trials, and AAV2 is the most common serotype utilized (Fig. 3).

\section{Advantages and Limitations of AAVs}

Based on the early discovery and the defined properties of AAVs, they have historically been the most characterized vectors for gene therapy. ${ }^{21}$ Early gene therapy clinical trials for nonneurological disorders employed this vector, which later led to its use in neurological disorders. Advantages for the use of AAV capsids, compared with other vectors for direct nervous system delivery, include that they are small and nonreplicative, can transfect dividing or nondividing cells, provide lasting or permanent 
TABLE 2. Current CNS gene therapy trials

\begin{tabular}{|c|c|c|c|c|c|c|c|}
\hline Disease & $\begin{array}{c}\text { Trial } \\
\text { Phase }\end{array}$ & $\begin{array}{c}\text { Viral } \\
\text { Vector }\end{array}$ & Serotype & Transgene & Delivery Route & Site of Delivery & Identifier* \\
\hline Parkinson's disease & I & AAV & 2 & AADC & Parenchymal & Striatum & NCT03065192 \\
\hline Parkinson's disease & II & AAV & 2 & GAD & Parenchymal & STN & NCT00643890 \\
\hline Parkinson's disease & 1 & AAV & 2 & AADC & Parenchymal & Striatum & NCT01973543 \\
\hline Parkinson's disease & I & AAV & 2 & GDNF & Parenchymal & Putamen & NCT04167540 \\
\hline Parkinson's disease & I & AAV & 2 & GAD & Parenchymal & STN & NCT00195143 \\
\hline Parkinson's disease & I/II & AAV & 2 & AADC & Parenchymal & Putamen & NCT02418598 \\
\hline Parkinson's disease & I & AAV & 2 & GDNF & Parenchymal & Striatum & NCT01621581 \\
\hline Parkinson's disease & I & AAV & 2 & NTN & Parenchymal & Putamen & NCT00252850 \\
\hline Parkinson's disease & I & AAV & 2 & AADC & Parenchymal & Putamen & NCT01395641 \\
\hline Parkinson's disease & II & AAV & 2 & NTN & Parenchymal & Putamen & NCT00400634 \\
\hline Parkinson's disease & II & AAV & 2 & AADC & Parenchymal & Putamen & NCT03562494 \\
\hline Parkinson's disease & $|/| \mid$ & AAV & 9 & GBA & Parenchymal & Cisternal & NCT04127578 \\
\hline Parkinson's disease & $|/| \mid$ & AAV & 2 & NTN & Parenchymal & Putamen/SN & NCT00985517 \\
\hline Parkinson's disease & I & AAV & 2 & AADC & Parenchymal & Striatum & NCT00229736 \\
\hline Mucopolysaccharidosis IIIA & $\| / / I I$ & AAV & rh10 & SGSH & Parenchymal & White matter & NCT03612869 \\
\hline Mucopolysaccharidosis IIIA & $|/| \mid$ & AAV & rh10 & SGSH & Parenchymal & White matter & NCT01474343 \\
\hline Mucopolysaccharidosis IIIB & $|/| \mid$ & AAV & 5 & NAGLU & Parenchymal & White matter & NCT03300453 \\
\hline MLD/ALD & $|/| \mid$ & AAV & rh10 & ARSA & Parenchymal & White matter & NCT01801709 \\
\hline Batten's disease & I & AAV & 2 & CLN2 & Parenchymal & White matter & NCT00151216 \\
\hline Batten's disease & 1 & AAV & rh10 & CLN2 & Parenchymal & White matter & NCT01161576 \\
\hline Batten's disease & $|/| \mid$ & AAV & rh10 & CLN2 & Parenchymal & White matter & NCT01414985 \\
\hline Huntington's disease & $|/| \mid$ & AAV & 5 & Huntingtin & Parenchymal & Striatum & NCT04120493 \\
\hline Alzheimer's disease & 1 & AAV & 2 & NGF & Parenchymal & Nucleus basalis & NCT00087789 \\
\hline Alzheimer's disease & II & AAV & 2 & NGF & Parenchymal & Nucleus basalis & NCT00876863 \\
\hline Alzheimer's disease & I & AAV & rh10 & APOE2 & Parenchymal & Cisternal & NCT03634007 \\
\hline AADC deficiency & I & AAV & 2 & AADC & Parenchymal & SN/VTA & NCT02852213 \\
\hline AADC deficiency & 1 & AAV & 2 & AADC & Parenchymal & Putamen & NCT02926066 \\
\hline Giant axonal neuropathy & 1 & AAV & 9 & Gigaxonin & Intrathecal & CSF & NCT02362438 \\
\hline CLN6 disease & $|/|||$ & AAV & 9 & CLN6 & Intrathecal & CSF & NCT02725580 \\
\hline Mucopolysaccharidosis II & I/II & AAV & 9 & IDS & Intrathecal & CSF & NCT03566043 \\
\hline CLN3 disease & $|/| \mid$ & AAV & 9 & CLN3 & Intrathecal & CSF & NCT03770572 \\
\hline Alzheimer's disease & I & AAV & 2 & TRAIL & Intrathecal/ventricular & CSF & NCT04133454 \\
\hline Duchenne muscular dystrophy & $|/| \mid$ & AAV & 9 & Micro-dystrophin & Intravenous & Systemic & NCT03368742 \\
\hline Duchenne muscular dystrophy & $|/| \mid$ & AAV & rh74 & GALGT2 & Intravenous & Systemic & NCT03333590 \\
\hline Duchenne muscular dystrophy & I & AAV & 9 & Mini-dystrophin & Intravenous & Systemic & NCT03362502 \\
\hline Duchenne muscular dystrophy & $|/| \mid$ & AAV & rh74 & Micro-dystrophin & Intravenous & Systemic & NCT03375164 \\
\hline Duchenne muscular dystrophy & $|/| \mid$ & AAV & 9 & ACCA & Intravenous & Systemic & NCT04240314 \\
\hline Fabry's disease & $|/| \mid$ & AAV & $2 / 6$ & GLA & Intravenous & Systemic & NCT04046224 \\
\hline Fabry's disease & $|/| \mid$ & AAV & 8 & GLA & Intravenous & Systemic & NCT04040049 \\
\hline Mucopolysaccharidosis II & $|/| \mid$ & AAV & $2 / 6$ & IDS & Intravenous & Systemic & NCT03041324 \\
\hline Mucopolysaccharidosis IIIA & I/II & AAV & 9 & SGSH & Intravenous & Systemic & NCT02716246 \\
\hline Mucopolysaccharidosis IIIA & $|/| \mid$ & AAV & 9 & SGSH & Intravenous & Systemic & NCT04088734 \\
\hline Mucopolysaccharidosis IIIB & $|/| \mid$ & AAV & 9 & NAGLU & Intravenous & Systemic & NCT03315182 \\
\hline Mucopolysaccharidosis I & $|/| \mid$ & AAV & $2 / 6$ & IDUA & Intravenous & Systemic & NCT02702115 \\
\hline Mucopolysaccharidosis I & I & AAV & 9 & IDUA & Intravenous & Systemic & NCT03580083 \\
\hline Pompe's disease & $|/| \mid$ & AAV & 8 & GAA & Intravenous & Systemic & NCT04174105 \\
\hline Pompe's disease & $|/| \mid$ & AAV & NA & GAA & Intravenous & Systemic & NCT04093349 \\
\hline Spinal muscular atrophy 2 & III & AAV & 9 & SMN & Intravenous & Systemic & NCT03505099 \\
\hline
\end{tabular}


TABLE 2. Current CNS gene therapy trials

\begin{tabular}{|c|c|c|c|c|c|c|c|}
\hline Disease & $\begin{array}{c}\text { Trial } \\
\text { Phase }\end{array}$ & $\begin{array}{l}\text { Viral } \\
\text { Vector }\end{array}$ & Serotype & Transgene & Delivery Route & Site of Delivery & Identifier* \\
\hline Spinal muscular atrophy 1 & $|/| \mid$ & AAV & 9 & SMN & Intravenous & Systemic & NCT02122952 \\
\hline Spinal muscular atrophy 1 & III & AAV & 9 & SMN & Intravenous & Systemic & NCT03306277 \\
\hline GM1 gangliosidosis (type II) & $|/| \mid$ & AAV & 9 & GLB-1 & Intravenous & Systemic & NCT03952637 \\
\hline Becker muscular dystrophy & I & AAV & 1 & FS344 & Intramuscular & Muscle & NCT01519349 \\
\hline Duchenne muscular dystrophy & $|/ /|$ & AAV & 1 & FS344 & Intramuscular & Muscle & NCT02354781 \\
\hline Duchenne muscular dystrophy & I & AAV & 2 & Mini-dystrophin & Intramuscular & Muscle & NCT00428935 \\
\hline Limb-girdle muscular dystrophy & 1 & AAV & 1 & SGCA & Intramuscular & Muscle & NCT00494195 \\
\hline Limb-girdle muscular dystrophy & I & AAV & 1 & SGCG & Intramuscular & Muscle & NCT01344798 \\
\hline Limb-girdle muscular dystrophy & $|/| \mid$ & AAV & rh74 & SGCA & Intramuscular & Muscle & NCT01976091 \\
\hline Limb-girdle muscular dystrophy & I & AAV & rh74 & Micro-dystrophin & Intramuscular & Muscle & NCT02376816 \\
\hline Pompe's disease & $1 / / 1$ & AAV & 1 & GAA & Intramuscular & Muscle & NCT00976352 \\
\hline Dysferlinopathies & I & AAV & rh74 & DYSF & Intramuscular & Muscle & NCT02710500 \\
\hline Alzheimer's disease & 1 & $\mathrm{ML}$ & NA & NGF & Parenchymal & Nucleus basalis & NCT00017940 \\
\hline Parkinson's disease & $|/ /|$ & LV & NA & ProSavin & Parenchymal & Striatum & NCT00627588 \\
\hline X-linked ALD & NA & LV & NA & ABCD1 & Parenchymal & NA & NCT03727555 \\
\hline MLD/ALD & $\mathrm{I} / \mathrm{II}$ & LV & NA & ARSA/ABCD1 & Intravenous & Systemic & NCT02559830 \\
\hline MLD & $\|$ & LV & NA & ARSA & Intravenous & Systemic & NCT03392987 \\
\hline Fabry's disease & I/II & LV & NA & GLA & Intravenous & Systemic & NCT03454893 \\
\hline Mucopolysaccharidosis IIIA & $1 / I \mid$ & LV & NA & SGSH & Intravenous & Systemic & NCT04201405 \\
\hline Mucopolysaccharidosis II & $|/| \mid$ & Lym & NA & IDS & Intravenous & Systemic & NCT00004454 \\
\hline
\end{tabular}

ABCD1 = ATP-binding cassette transporter; $A C C A=$ acetyl $-\mathrm{CoA}$ carboxylase alpha; $A L D=$ adrenoleukodystrophy; $A R S A=$ arylsulfatase $A ; A S P A=$ aspartoacylase; CLN2 = late infantile neuronal ceroid lipofuscinosis type 2; CLN3 = CLN type 3; CLN6 = CLN type 6; DYSF = dysferlin; FS344 = follistatin; GAA = glucosidase alpha; GBA = glucosylceramidase beta; GLA = galactosidase alpha; GLB-1 = galactosidase beta 1; IDS = iduronate 2-sulfatase; IDUA = alpha-L-iduronidase; LV = lentivirus; Lym = lymphocytes; $\mathrm{ML}=$ Maloney leukemia; $\mathrm{MLD}=$ metachromatic leukodystrophy; NA = not applicable; NAGLU = N-acetyl-alpha-glucosaminidase; $\mathrm{NGF}=$ nerve growth factor; NTN = neurturin; ProSavin = encodes tyrosine hydroxylase, AADC, and GTP-cyclohydrolase 1; SGCA = sarcoglycan alpha; SGCG = sarcoglycan gamma; $\mathrm{SGSH}=\mathrm{N}$-sulfoglucosamine sulfohydrolase; $\mathrm{SMN}$ = survival motor neuron; $\mathrm{SN}$ = substantia nigra; TRAIL = tumor necrosis factor-related apoptosis-inducing ligand; VTA = ventral tegmental area.

${ }^{*}$ ClinicalTrials.gov.

gene expression, and are not pathogenic in humans. ${ }^{16,18,19 \text {, }}$ ${ }_{22,23}$ Limitations of AAVs and other vectors include quality or transfection potency differences based on production methodology, limited cloning capacity (large genes cannot be readily used in this vector), high cost of production (all viral vectors), inability to tune or turn on/off gene expression (all viral vectors), and frequent humoral immunity that can limit the use or transduction efficiency for systemic applications. ${ }^{16,18,19,22,23}$

\section{Direct Nervous System Viral Vector Delivery Bulk Flow Properties (convection)}

Convective delivery utilizes a small hydrostatic pressure gradient (bulk flow) derived from a syringe pump to drive infusate from a specially designed cannula through the interstitial spaces of the nervous system. ${ }^{1,2}$ Because CED relies on bulk flow for the distribution of infusate, it overcomes the limitations of currently available drug delivery methods to the CNS, as it bypasses the BBB and can homogeneously distribute large viral vectors without diffusive limitations. ${ }^{24-29}$ Particularly, CED of AAVs is now primarily used to therapeutically manipulate dis- eased brain circuits in disorders that are presently ineffectively treated or not treatable. These gene-modifying approaches can exploit the properties of CED and biological features of AAV serotypes to tailor treatments that are specific to neurological disease anatomy and pathobiology (Table 2).

\section{Bypassing the BBB}

Because convective delivery relies on interstitial delivery of infusate, viral vectors are directly perfused into the nervous system parenchyma bypassing the BBB. ${ }^{1,2}$ Therapeutic AAV vectors are large molecular agents $(25 \mathrm{~nm})$ and physically do not pass across the tight junctions of the $\mathrm{BBB}$ when administered systemically. ${ }^{16}$ However, the inability of viral vectors to cross the BBB makes them ideal agents to deliver directly to the nervous system parenchyma as they are sequestered on the abluminal side of the BBB. This feature, along with cell-specific transduction, reduces systemic exposure of viral vectors that can be associated with de novo antibody formation and/or eliminates the inflammatory effects coupled with existing antibodies directed to infused viral vectors. 

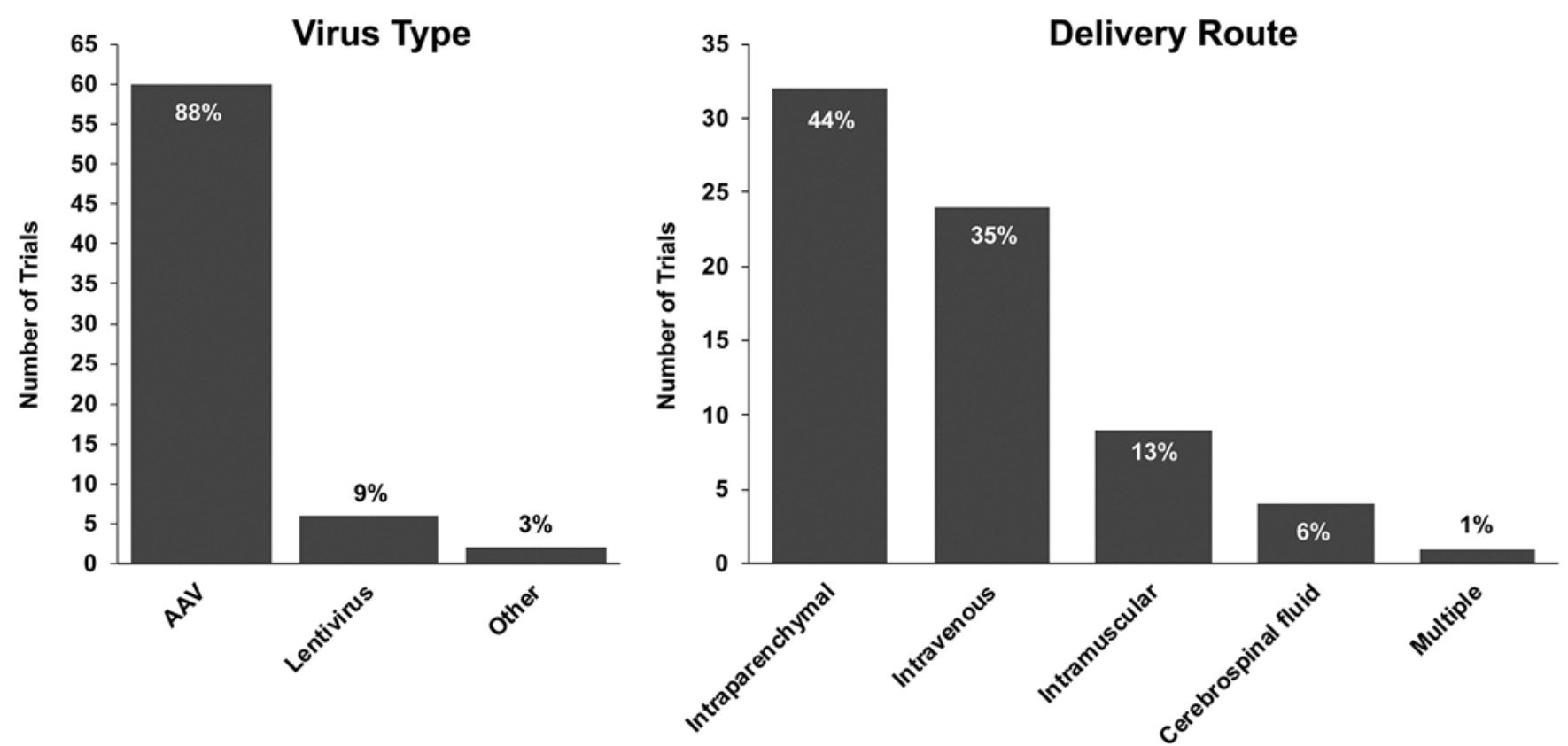

FIG. 1. Frequency of virus types employed and routes of delivery for current gene therapy clinical trials for nervous system disorders. Left: Frequency (percentage of all gene therapy trials for nervous system disorders) of viral vector type used in gene therapy clinical trials. AAV vectors are the most commonly used vectors in nervous system gene therapy trials (used in $88 \%$ of all trials). Right: Frequency (percentage of all gene therapy trials for nervous system disorders) of the route of delivery of viral vectors in gene therapy clinical trials. The most common route of delivery of viral vectors for nervous system gene therapy is direct convective delivery to the parenchyma ( $44 \%$ of trials).

\section{Targeted Delivery of Viral Vectors}

A unique property of convective distribution of viral vectors is the ability to precisely target and perfuse anatomical structures and/or regions of the CNS. The stereo- tactic placement of infusion cannulae permits the accurate anatomical targeting (regional, nuclear, and/or subnuclear) of critical diseased areas for perfusion within the nervous system. ${ }^{913,30,31}$ Because viral vectors are large and capsids
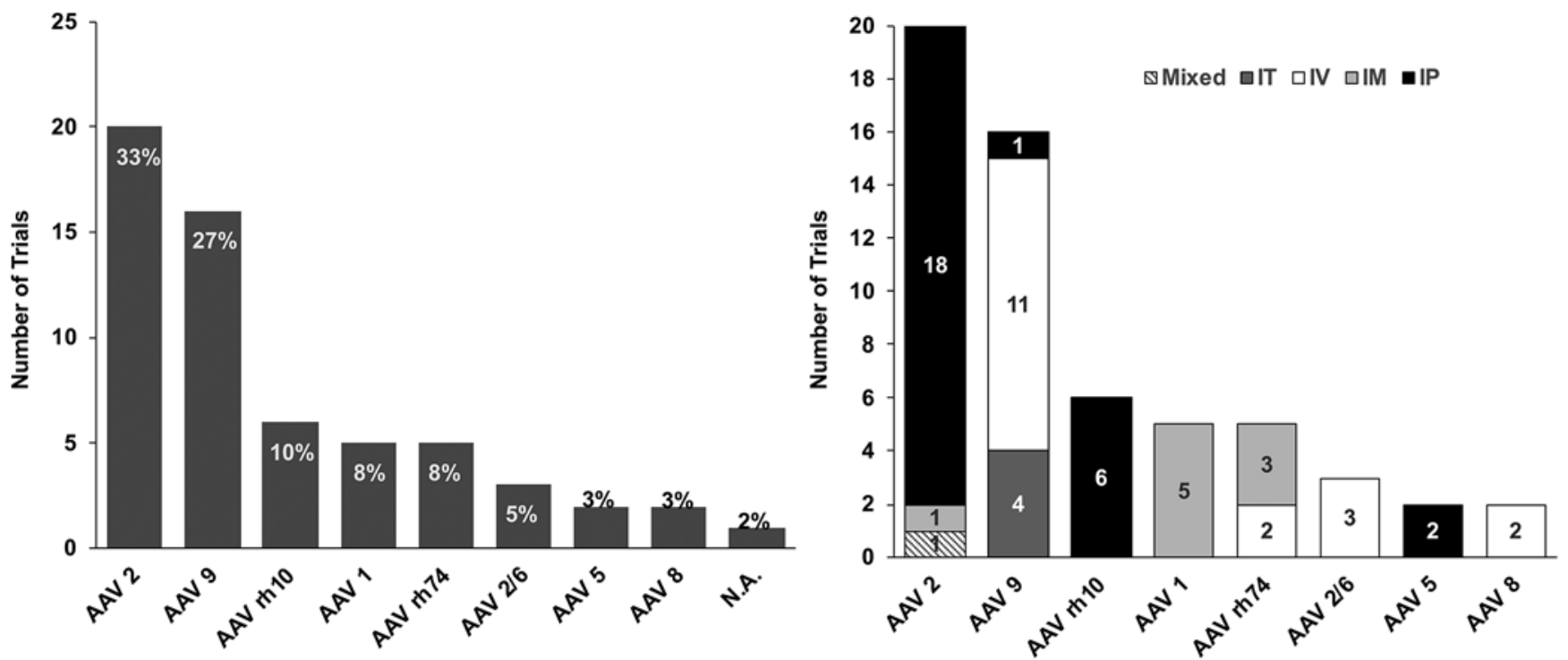

FIG. 2. Frequency of $A A V$ serotypes and routes of delivery used in gene therapy clinical trials that employ AAV vectors (clinical trials using AAV, 60 [88\% of nervous system gene therapy trials]). Left: Frequency of each of the various AAV serotypes used in nervous system gene therapy clinical trials that employ AAV. Right: AAV serotype used and route of delivery (number of trials with associated delivery route in coded portion of bar) in nervous system gene therapy clinical trials that employ AAV. IM = intramuscular; IP = intraparenchymal; IT = intrathecal; IV = intravenous; mixed = more than 1 route; N.A. = not available. 


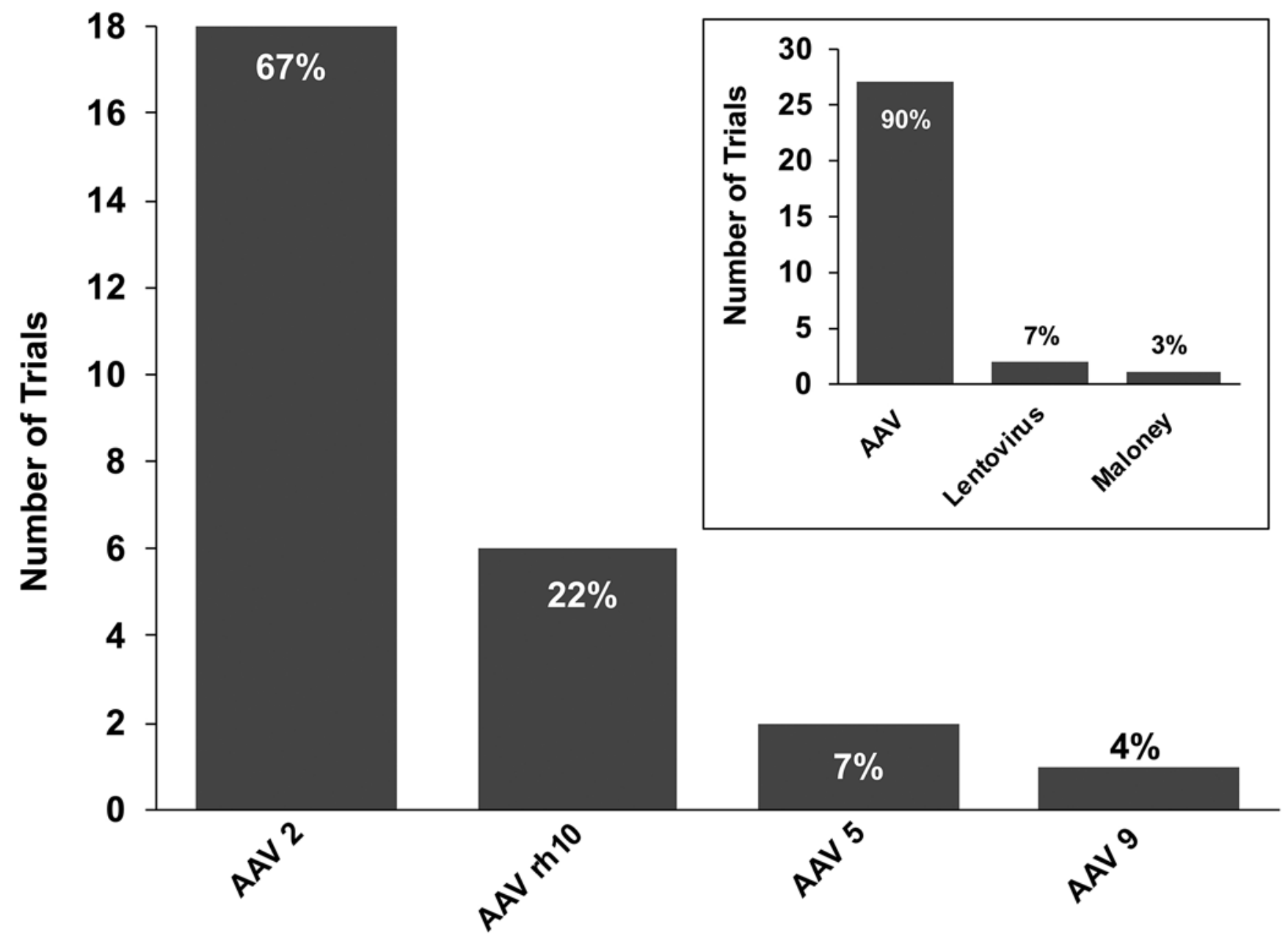

FIG. 3. Serotype and frequency of the use of AAV vectors in nervous system gene therapy clinical trials using direct intraparenchymal delivery. Inset: Types of viral vectors used for direct intraparenchymal delivery in nervous system gene therapy clinical trials. Ninety-one percent of all direct intraparenchymal delivery clinical trials use AAV vectors.

are not associated with significant diffusion, the transgene expression is limited (exclusive of antero- and/or retrograde transport; see below) to the anatomically perfused region. This property reduces or eliminates the potential for off-target effects, enhancing the safety of therapeutic transgene expression by viral vectors directly distributed by convective delivery. Moreover, because diseased brain regions can be precisely targeted and completely perfused, insights into transgene product efficacy and the therapeutic viability of targets can be defined.

\section{Homogeneous Viral Vector Distribution}

The bulk flow properties of CED result in the homogeneous distribution of AAV capsids across the perfused region of tissue and ensure uniform exposure of the tissue to the vector. ${ }^{2,32,33}$ Previously, quantitative autoradiography was used to define the convective interstitial distribution of AAV in the white and gray matter of rodents and nonhuman primates. ${ }^{33}$ These data demonstrated that AAV vectors distributed across the perfused region (both in white and in gray matter) in a homogeneous manner that was defined by a square-shaped (steep drop-off in concentration at the infused region edges and uniform high concentration across the perfused region) distribution profile. Because the virus is uniformly distributed across the target, the concentration (i.e., dose per volume of perfused tissue) of capsids can be estimated across the treated area.

\section{Consistent Distribution of Viral Vector}

Convective distribution of AAV is reliable. A number of studies have quantified (via quantitative autoradiography, transgene expression, and imaging) the volume of infusion to volume of tissue perfusion of AAV distributed by convective delivery. Like nonviral studies, investigations into viral vector delivery have demonstrated that increases in infusion volume result in linear increases $\left(\mathrm{R}^{2}\right.$ coefficient $>0.90)$ in tissue drug volume of distribution. Volume of infusion-to-volume of tissue distribution ratios for AAV vectors have ranged from $1: 1$ to $3: 1 .^{33,34}$ These data indicate that for every milliliter of infusate that is delivered, 1 to 3 $\mathrm{ml}$ of tissue volume is perfused. Understanding the volume of infusion-to-volume of distribution ratios for viral 
vector tissue perfusion also permits for accurate preinfusion estimation of infusion volume on an individualized basis for anatomical targets throughout the CNS.

\section{Axonal Transport of Viral Vectors}

Using AAV vectors, axonal transport from the primary site of convective perfusion occurs in an antero- and/or retrograde manner (Table 1). Previous work has demonstrated that AAV delivered by CED can be transported to interconnected regions by antero- or retrograde axonal transport that is serotype dependent. While AAV2 undergoes anterograde transport and AAV6 undergoes retrograde transport, recent studies have demonstrated that AAV serotypes 1, 8, and 9 undergo both anterograde and retrograde transport. $7,19,35$ Furthermore, the frequency of transport for AAV9 demonstrated manipulability with receptor availability. ${ }^{7,19,35}$ This biological property has critical implications for the treatment of neurological disorders by convective delivery. Specifically, perfusion of a single anatomical target with AAV can be used for distant widespread transgene expression that is defined by anterograde and/or retrograde transport depending on serotype. Manipulation of these interconnected sites for therapeutic gain can be selectively influenced by the target selection and AAV serotype.

\section{Viral Vector Cellular Tropism}

Because AAV vectors can stably transduce dividing and postmitotic cells in the CNS with high efficiency, they have been the focus of translational and clinical studies using direct delivery for treatment. Previous studies have demonstrated that serotype defines cellular tropism after convective delivery of AAV vectors (Table 1). ${ }^{7,19,35}$ Serotypes are defined as antigenically distinct viral capsids with varying receptor affinities. While AAV2 has an affinity for neurons, serotypes $1,5,8,9$, and rh10 have an affinity for neurons, astrocytes, and/or nonneuronal cells. The basis for the cellular tropism is serotype affinity for different cellular receptors and co-receptors., ${ }^{79,35}$ Other potential factors affecting tropism and axonal transport include vector promoter or sequence, purification, and production method. This serotype-specific tropism can be exploited with chemical modifications of virus capsids or production of hybrid capsids ${ }^{7,19,35}$ to precisely treat diseasespecific cells in the nervous system and avoid transduction of other cells that could elicit an immune reaction to nonself proteins (see Safety).

\section{Perivascular Distribution}

Perivasular spaces provide low-resistance pathways for convective flow and infusate distribution (Fig. 4). During CED, AAV infusate can enter perivascular spaces and preferentially travel within these cerebral vasculature pathways. If the vasculature is confined to the targeted anatomical structure, this mechanism will contribute to vector spread. However, perivascular flow can lead to offtarget distribution. Specifically, intraputaminal infusions are prone to perivascular distribution along the lenticulostriate vessels. ${ }^{36}$ Use of MR-guided infusion is essential to monitor perivascular distribution and minimizing this ef-

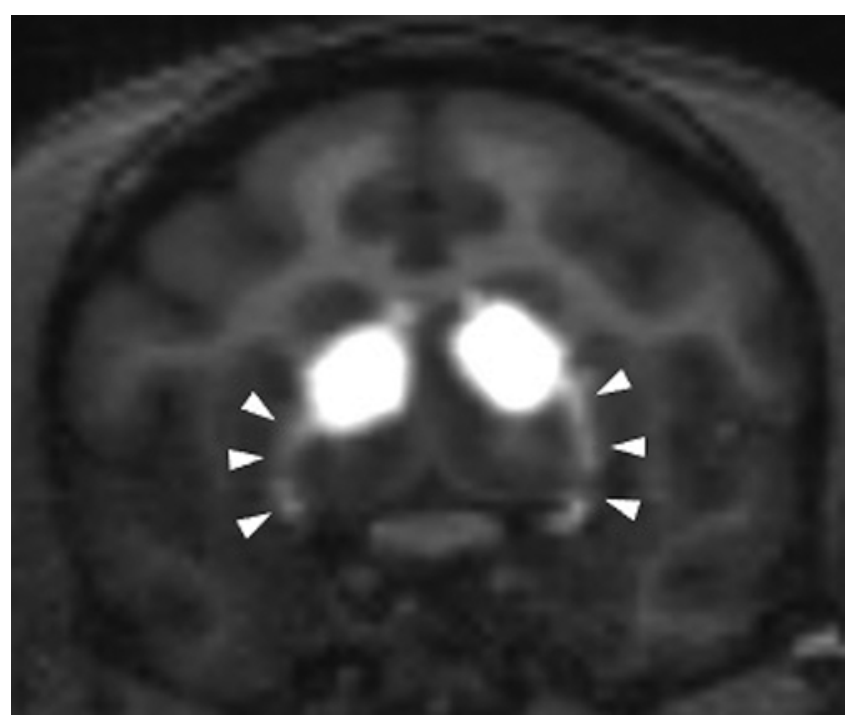

FIG. 4. Coronal T1-weighted MR image obtained in a nonhuman primate brain after infusion of a surrogate imaging tracer (gadoteridol) with AAV vector into the putamen. The low-resistance pathways for convective flow are demonstrated by the perfusion preferentially along the lenticulostriate vessels that run perpendicular to the long axis of the putamen (arrowheads).

fect by advancing the cannula tip away from infusate preferentially flowing along the perivascular spaces ("infuseas-you-go") (Video 1). ${ }^{37}$

VIDEO 1. Video demonstrating the infuse-as-you-go technique in a nonhuman primate to improve perfusion of elongated structures (e.g., putamen). From Sudhakar V, Naidoo J, Samaranch L, et al. Infuse-as-you-go convective delivery to enhance coverage of elongated brain targets: technical note. J Neurosurg. Published online July 12, 2019. doi:10.3171/2019.4.JNS19826. Copyright Krystof S.

Bankiewicz. Published with permission. Click here to view.

Finally, a perivascular pump mechanism plays an important role in CSF administration and distribution of AAV vectors that lead to the cortical spread of AAV..$^{38-40}$

\section{Imaging of Viral Vector Distribution and Expression}

Co-infusion of a surrogate imaging tracer (gadoteridol) with real-time MRI is the only imaging modality that is currently being used in CNS gene therapy clinical trials. This technique has been shown to accurately and reliably assess AAV perfusion and transgene expression at the site of perfusion (Fig. 5). ${ }^{34,41}$ The ability to noninvasively monitor AAV vector infusion in real time allows for confirmation of cannula tip placement, permits verification of infusion initiation, enables adjustment of cannula positioning (or repositioning), ensures adequate perfusion of the target, identifies infusate leak back, provides an understanding of convective properties in disease states, and avoids perfusion outside of the target. ${ }^{2,3,14,15,42}$ These features are essential to defining the efficacy of viral therapeutic approaches in various regions of the nervous system, supporting anatomical dosing strategies (the association between percent target perfusion and clinical effect) and enhancing the safety of this delivery paradigm by avoiding or limiting perfusion of nontarget areas. 

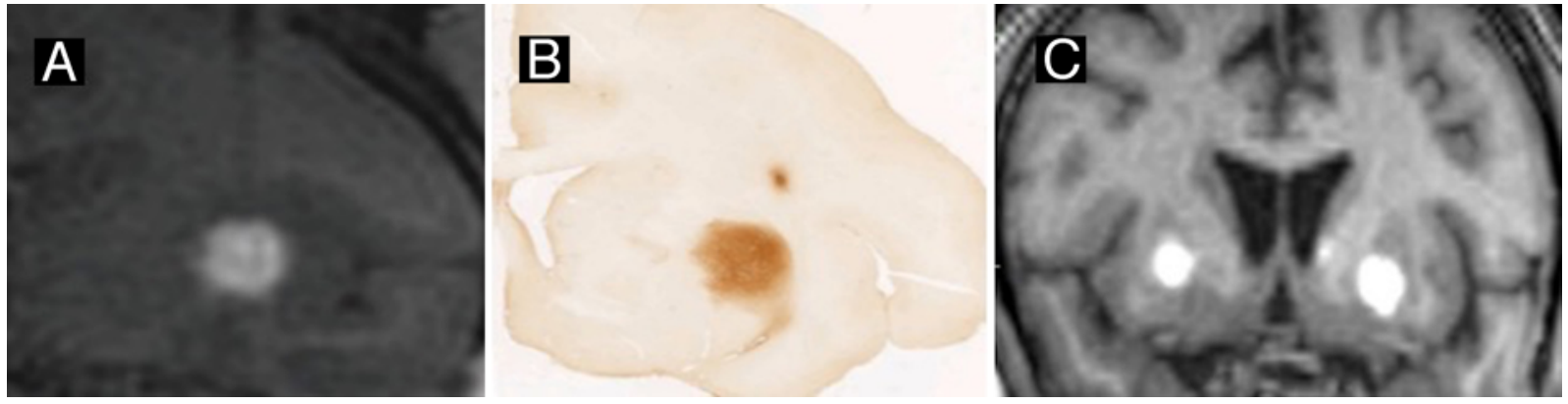

FIG. 5. A: MR image of a surrogate imaging tracer (gadoteridol) co-infused AAV vector with the gene for GDNF in a nonhuman primate. B: Co-infused gadoteridol matches AAV2-GDNF distribution on MRI and transgene expression (brown) from the corresponding tissue section (immunohistochemical staining for GDNF). C: Coronal MR image obtained in a patient who underwent putaminal infusion of AAV2-GDNF for PD. Panel B: Reprinted from Richardson RM, Kells AP, Rosenbluth KH, et al. Interventional MRI-guided putaminal delivery of AAV2-GDNF for a planned clinical trial in Parkinson's disease. Mol Ther. 2011;19(6):1048-1057. (C2011 The American Society of Gene \& Cell Therapy. Published by Elsevier Inc. Permission for reuse via a CC BY-ND-ND 4.0 license (https://creativecommons.org/licenses/by-nd/4.0/).

\section{Biomarker Assessment of Effect}

Based on the ability to determine the distribution of viral vectors in real time using MRI and the established biological features of individual neurological disorders, early biomarker assessment is possible to determine the impact of treatment before a clinical effect. Particularly, the assessment of transgene expression and/or treatment-related change on imaging modalities (MRI, PET, and/or SPECT), blood, and/or CSF markers can provide an early understanding of treatment impact and dosing relationships. ${ }^{12,13}$, ${ }^{42-44}$ Clinically, specific assessment biomarkers have been tailored to assess the early impact of treatment in various neurological disease states, including Parkinson's disease (PD) (PET and CSF metabolites) and aromatic L-amino acid decarboxylase (AADC) deficiency (PET, SPECT, and CSF metabolites)..$^{12,13,42,43}$

\section{Safety \\ Convective Delivery}

Direct convective delivery of a variety of viral vectors to the nervous system is safe (Table 2). Viral vectors that are frequently used in translational and clinical studies can be infused over small or large regions or targets in the nervous system safely. Convective delivery of AAV capsids has been the most defined (Tables 1 and 2; Figs. $1-3)$. These data are consistent with the safety of convective perfusion, including diseased eloquent regions, using nonviral therapies. Moreover, because the viral vectors are sequestered on the abluminal side of the BBB and delivered in small total amounts, the development of new antibodies or an immune reaction associated with existing antibodies is reduced or eliminated (negating the need for immune suppression or steroids after treatment) and could permit repeat direct infusion of the AAV if needed at later points in time..$^{25,45}$

\section{Transgene Expression}

While clinically relevant immune responses have not been found in trials after direct delivery of AAVs, previous animal studies have demonstrated that transduction of non-self or foreign proteins can elicit a humoral and cellular immune response. ${ }^{16}$ Moreover, it appears that the extent of the immune response is dependent on the cell type transduced. Specifically, the immune response was limited to local transient inflammation when AAV1 and AAV2 (only neuronal transduction) were delivered directly into the brain. ${ }^{45,46}$ However, because AAV9 transduction includes antigen-presenting cells (as well as astrocytes and neurons), transgene expression by cells of this serotype can elicit a humoral and cellular response that can lead to neuronal cell death. ${ }^{47}$

\section{Vector Infusion Technology}

Infusion equipment used for convective delivery of viral vectors is similar to the equipment used for delivery of nonviral therapeutic agents. The equipment is composed of a noncompliant syringe pump, syringe, and interconnecting infusate line (silicate) that connects the syringe to the cannula (ceramic and silicate) and does not adhere to viral capsids. Specially designed stepped infusion cannulae are used for viral vector infusions. ${ }^{3,48}$ There are two available frameless stereotactic systems that are MRscanner compatible for CED. ${ }^{41,49-51}$ These systems have been adapted (i.e., they were designed for intraoperative MRI placement of deep brain stimulator leads) for cannula placement, infusion imaging, and cannula adjustment during CED. A new MR-compatible frameless stereotactic ball-joint guide array that was designed for CED can provide a highly facile, lower-profile, more economical platform that allows a streamlined approach for CED. ${ }^{52}$

\section{Clinical Applications}

Current use of AAV vectors exploits the described properties of direct delivery and viral capsid transport or trophism. The timing of gene therapy is disease and therapy specific. Generally, while symptom-modifying or replacement (with intact neurocircuitry) gene treatment can be employed later in the disease course, treatment targeting neural restoration (requiring intact neurons and/or cells) or disease (natural history) modification is often best applied earlier in the disease course. To best illustrate these features, we describe the clinical applications in exemplars. 


\section{Neurodegenerative Diseases}

\section{PD (symptomatic; AAV2-AADC)}

PD typically manifests with tremor, rigidity, bradykinesia, and gait dysfunction. Five to 10 years after levodopa medical treatment initiation, PD patients develop disabling "on" (often characterized by dyskinesias) and "off" (characterized by waning effect of medication on motor findings) fluctuations that severely limit the effectiveness of levodopa. ${ }^{53-55}$ Postmortem analysis in levodopa-treated PD patients reveals profound striatal-nigral loss (compared with controls) of AADC, which enzymatically converts levodopa to dopamine..$^{56}$ The lack of AADC in the striatum is believed to underlie the medically intractable (on/off fluctuations) features of long-term use of levodopa. Subsequently, replacement of striatal AADC in PD is an attractive target to provide symptomatic improvement in conjunction with oral levodopa supplementation.

Recently, Bankiewicz and colleagues used CED of AAV2-AADC to the bilateral putamen to restore expression of AADC to the putamen and distant interconnected striatal nigra circuits (globus pallidus, subthalamic nucleus [STN], and substantia nigra pars reticulata) via anterograde transport in PD patients. ${ }^{6,13}$ Bilateral transfrontal cannula placement (up to 3 infusions per side) was used to perfuse the postcommissural putamen. Putaminal coverage was associated with increasing infusion volume $(21 \%$, $34 \%$, and $43 \%$ mean putaminal coverage with increasing infusion volume). Increasing perfusion correlated with F-DOPA (L-6- $\left[{ }^{18} \mathrm{~F}\right]$ fluoro-3,4-dihydroxyphenylalanine) PET uptake and a reduction in levodopa requirements $(15 \%, 33 \%$, and $42 \%$ reduction in antiparkinsonian medications at 6 months). ${ }^{13}$ To enhance putaminal perfusion and clinical impact, a new trial employing a posterior (occipital) approach through a single cannula pass per side using the infuse-as-you-go method is being performed (Video 1). ${ }^{37}$

\section{PD (symptomatic; AAV2-glutamic acid decarboxylase)}

Dopaminergic neuronal loss in the substantia nigra pars compacta leads to metabolic and functional connectivity changes in the striatum and related motor circuitry, including overactivation of the STN. Interruption of STN hyperactivity using deep brain stimulation has been successful in ameliorating PD symptomatology. Because glutamic acid decarboxylase (GAD) catalyzes glutamate to GABA (primary inhibitory neurotransmitter in the CNS), direct delivery of AAV2-GAD to the STN has been performed to biologically reduce STN overactivity in PD. ${ }^{57-59}$ Trials delivering AAV2-GAD to the STN have demonstrated functional improvements in PD patients that have persisted for at least 1 year..$^{57-59}$ These studies have demonstrated that new polysynaptic pathways connecting the STN to cortical motor regions developed after AAV2-GAD delivery may underlie clinical improvement. ${ }^{60}$ Later-stage trials will better establish the clinical significance of AAV2-GAD.

\section{PD (regenerative; AAV2-glial cell-derived neurotrophic factor)}

The neuropathology of PD is characterized by the loss of dopaminergic neurons in the substantia nigra pars compacta. Glial cell-derived neurotrophic factor (GDNF) functions via a signaling complex composed of RET receptor tyrosine kinase and GDNF $\alpha 1{ }^{61-63}$ Several groups have demonstrated that GDNF promotes embryonic dopaminergic neuron survival in vitro. ${ }^{8,31,64,65}$ Based on these data, rodent and nonhuman primate PD models were treated with intraputaminal delivery of AAV2-GDNF. These studies demonstrated the rescue or regeneration of dopaminergic neurons in the putamen and interconnected striatum and substantia nigra pars compacta that was associated with lasting PD symptom improvement. ${ }^{8,66-69}$

To exploit these biological findings for striatal-nigral regeneration, transfrontal putaminal infusion of AAV2GDNF in patients with moderate to severe stage PD was performed. ${ }^{42}$ Data from this phase I trial demonstrated that CED of AAV2-GDNF was safe and well tolerated. Putaminal perfusion volume ( $26 \%$ of posterior putamen) via the transfrontal approach was limited because of infusion geometry (perpendicular to the long axis of the putamen via this approach) and total infusion volume ( $450 \mu \mathrm{l}$ per side). Despite limited putaminal perfusion, PD signs and symptoms and medication dosing remained stable with long-term follow-up (> 36 months). Similar to the surgical strategy used to increase putaminal perfusion volume in the recent AAV2-AADC trial, a phase Ib trial is enrolling PD patients for AAV2-GDNF infusion that employs an occipital approach with convective perfusion along the long axis of the putamen (infuse-as-you-go). ${ }^{37}$

\section{Neurotransmitter Disorders}

\section{AADC Deficiency}

AADC is the key enzyme for biosynthesis of the catecholamines dopamine and serotonin. It catalyzes decarboxylation of levodopa to dopamine and 5-HTP (5-hydroxytryptophan) to serotonin. Patients with AADC deficiency typically manifest with hypotonia, oculogyric seizures, hypokinesia, dystonia, and autonomic dysfunction. ${ }^{70}$ The life expectancy for patients is 5 to 6 years. Early clinical studies employed convective perfusion of portions of the putamen with AAV2-AADC, resulting in modest improvement, including motor score improvement in all patients and a median increase in CSF homovanillic acid of $25 \mathrm{nmol} / \mathrm{L}$ but no significant change in 5-HIAA (hydroxyindoleacetic acid). ${ }^{71,72}$ Because AAV2-AADC does not undergo significant retrograde transport (Table 1), putaminal CED of AAV2-AADC may not result in the extensive transduction of catecholamine-secreting neurons. To exploit the direct site of delivery impact and the anterograde transport properties of AAV2-AADC to effect catalyzation of dopamine and serotonin, nonhuman primates were infused in the substantia nigra and ventral tegmental areas. These studies demonstrated strong increased expression of AADC in these target structures with robust expression of AADC in anterograde regions of interconnected distant regions of the brain. ${ }^{73}$ Because AADC-deficient patients have intact nigrostriatal and mesolimibic pathways, trials are being performed to perfuse the substantia nigra and ventral tegmental area to directly target regions that produce levodopa to promote dopamine synthesis and impact regions via anterograde transport (Fig. 6). These trials are ongoing with promising clinical results. 

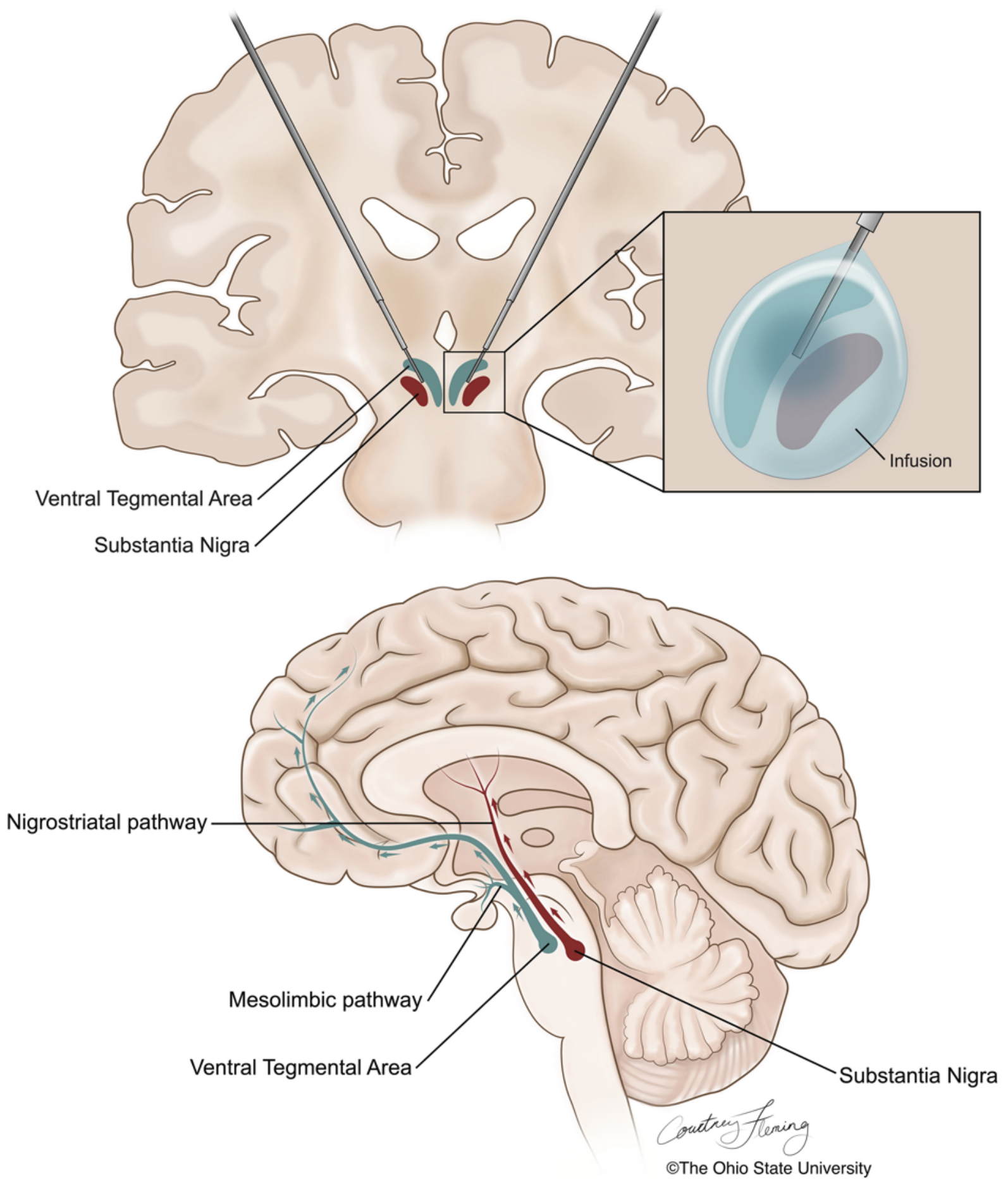

FIG. 6. Illustration demonstrating direct convective delivery of gene therapy for manipulation of neurocircuitry in AADC deficiency disease using AAV vector containing the AADC gene. Upper: Coronal view. Anatomical treatment targets for treatment include the substantia nigra and ventral tegmental areas, which are critical dopamine-producing areas (via conversion of levodopa to dopamine). Inset: These anatomical structures are perfused with AAV-AADC (blue) to replace deficient AADC. Lower: Sagittal view. Because AADC-deficient patients have intact nigrostriatal and mesolimbic pathways, perfusion of the substantia nigra and ventral tegmental area have potent distant effects via anterograde (arrows) transport in these pathways. Copyright The Ohio State University. Published with permission. 


\section{Metabolic Disorders}

Lysosomal Storage Diseases

AAV gene therapy has shown promising results for lysosomal storage disease (LSD). LSDs are difficult to treat, as they require enzyme replacement therapy and enzymes do not cross the BBB. Direct infusion gene therapy can potentially overcome this obstacle. Mucopolysaccharidosis (MPS) is caused by the accumulation of glycosaminoglycans in the lysosome due to the inability of degradation of mucopolysaccharides. Currently, there are gene therapy trials for MPS I (Hurler infantile syndrome), MPS II (Hunter syndrome), MPS IIIA/IIIB, and MPS VI that employ direct intraparenchymal delivery of viral vectors for gene therapy replacement of enzymes. These trials exploit the low-resistance white matter tracts to perfuse large regions of the cerebrum with vector throughout the brain (Table 2). ${ }^{74,75}$

\section{Future Implications}

While direct convective delivery of viral vectors for CNS gene therapy is being increasingly used (Table 2), critical advances are needed for its continued adoption and expanded application. First, a deeper understanding of AAV and other vectors, as well as new molecular biological insights into neurological disorders and characterization of the convective distribution of viral vectors, has facilitated the current and growing application of direct CNS gene therapy delivery. Additional understanding of disease biology and delivery properties will catalyze therapeutic expansion across neurological disease not traditionally treated by neurosurgeons. Second, it is likely that similar-sized nonviral vectors with tailored cellular trophism and transport characteristics will be developed. This will permit the personalized application of intraparenchymal disease-modifying CNS gene treatments broadly. Third, delivery device improvements have driven the expanded use of convective delivery for CNS gene therapy and will be essential for growth. The development of cannula placement devices that will not require dedicated software, will lower production costs, are adaptable to multiple contemporaneous infusions, enhance time efficiency, and provide a universal platform will increase the use of direct CNS gene therapy delivery. Finally, similar to any new surgical treatment, defined training and dedicated sites with frequent case throughput will be critical to advance the field and ensure consistent outcomes across surgeons and sites.

\section{Conclusions}

Convective perfusion of viral vectors provides an opportunity to manipulate diseased circuits in neurological disease in a manner not possible with other putative therapeutics. The properties of CED in conjunction with differences in AAV serotypes provide the opportunity for local and/or distant effects (via either anterograde or retrograde axonal transport) for the treatment or repair of diseased nervous system pathways. These features provide new therapeutic prospects for incompletely treated or untreatable disorders.

\section{Acknowledgments}

This work was supported by the National Institute of Neurological Disorders and Stroke of the National Institutes of Health.

\section{References}

1. Bobo RH, Laske DW, Akbasak A, et al. Convection-enhanced delivery of macromolecules in the brain. Proc Natl Acad Sci U S A. 1994;91(6):2076-2080.

2. Lonser RR, Sarntinoranont M, Morrison PF, Oldfield EH. Convection-enhanced delivery to the central nervous system. J Neurosurg. 2015;122(3):697-706.

3. Fiandaca MS, Forsayeth JR, Dickinson PJ, Bankiewicz KS. Image-guided convection-enhanced delivery platform in the treatment of neurological diseases. Neurotherapeutics. 2008;5(1):123-127.

4. Hadaczek P, Stanek L, Ciesielska A, et al. Widespread AAV1and AAV2-mediated transgene expression in the nonhuman primate brain: implications for Huntington's disease. Mol Ther Methods Clin Dev. 2016;3:16037.

5. Kells AP, Hadaczek P, Yin D, et al. Efficient gene therapybased method for the delivery of therapeutics to primate cortex. Proc Natl Acad Sci U S A. 2009;106(7):2407-2411.

6. Ciesielska A, Mittermeyer G, Hadaczek P, et al. Anterograde axonal transport of AAV2-GDNF in rat basal ganglia. Mol Ther. 2011;19(5):922-927.

7. Castle MJ, Gershenson ZT, Giles AR, et al. Adeno-associated virus serotypes 1,8 , and 9 share conserved mechanisms for anterograde and retrograde axonal transport. Hum Gene Ther. 2014;25(8):705-720.

8. Eberling JL, Kells AP, Pivirotto P, et al. Functional effects of AAV2-GDNF on the dopaminergic nigrostriatal pathway in parkinsonian rhesus monkeys. Hum Gene Ther. 2009;20(5):511-518.

9. Salegio EA, Samaranch L, Kells AP, et al. Guided delivery of adeno-associated viral vectors into the primate brain. $A d v$ Drug Deliv Rev. 2012;64(7):598-604.

10. Salegio EA, Samaranch L, Kells AP, et al. Axonal transport of adeno-associated viral vectors is serotype-dependent. Gene Ther. 2013;20(3):348-352.

11. Samaranch L, Pérez-Cañamás A, Soto-Huelin B, et al. Adeno-associated viral vector serotype 9-based gene therapy for Niemann-Pick disease type A. Sci Transl Med. 2019;11(506):eaat3738.

12. Deverman BE, Ravina BM, Bankiewicz KS, et al. Gene therapy for neurological disorders: progress and prospects. Nat Rev Drug Discov. 2018;17(10):767.

13. Christine CW, Bankiewicz KS, Van Laar AD, et al. Magnetic resonance imaging-guided phase 1 trial of putaminal AADC gene therapy for Parkinson's disease. Ann Neurol. 2019;85(5):704-714.

14. Su X, Kells AP, Salegio EA, et al. Real-time MR imaging with Gadoteridol predicts distribution of transgenes after convection-enhanced delivery of AAV2 vectors. Mol Ther. 2010;18(8):1490-1495. Published correction in Mol Ther. 2012;20(2):468.

15. Lonser RR. Imaging of convective drug delivery in the nervous system. Neurosurg Clin N Am. 2017;28(4):615-622.

16. Hudry E, Vandenberghe LH. Therapeutic AAV gene transfer to the nervous system: a clinical reality. Neuron. 2019;102(1):263.

17. Schultz BR, Chamberlain JS. Recombinant adenoassociated virus transduction and integration. Mol Ther. 2008;16(7):1189-1199.

18. Wang D, Tai PWL, Gao G. Adeno-associated virus vector as a platform for gene therapy delivery. Nat Rev Drug Discov. 2019;18(5):358-378.

19. Castle MJ, Turunen HT, Vandenberghe LH, Wolfe JH. Con- 
trolling AAV tropism in the nervous system with natural and engineered capsids. Methods Mol Biol. 2016;1382:133-149.

20. Totsch SK, Schlappi C, Kang KD, et al. Oncolytic herpes simplex virus immunotherapy for brain tumors: current pitfalls and emerging strategies to overcome therapeutic resistance. Oncogene. 2019;38(34):6159-6171.

21. Carter BJ. Adeno-associated virus and the development of adeno-associated virus vectors: a historical perspective. Mol Ther. 2004;10(6):981-989.

22. Verdera HC, Kuranda K, Mingozzi F. AAV vector immunogenicity in humans: a long journey to successful gene transfer. Mol Ther. 2020;28(3):723-746.

23. Daya S, Berns KI. Gene therapy using adeno-associated virus vectors. Clin Microbiol Rev. 2008;21(4):583-593.

24. Blasberg RG, Patlak C, Fenstermacher JD. Intrathecal chemotherapy: brain tissue profiles after ventriculocisternal perfusion. J Pharmacol Exp Ther. 1975;195(1):73-83.

25. Muldoon LL, Alvarez JI, Begley DJ, et al. Immunologic privilege in the central nervous system and the blood-brain barrier. J Cereb Blood Flow Metab. 2013;33(1):13-21.

26. Langer R. New methods of drug delivery. Science. 1990;249(4976):1527-1533.

27. Pardridge WM. Drug delivery to the brain. J Cereb Blood Flow Metab. 1997;17(7):713-731.

28. Strasser JF, Fung LK, Eller S, et al. Distribution of 1,3-bis(2chloroethyl)-1-nitrosourea and tracers in the rabbit brain after interstitial delivery by biodegradable polymer implants. $J$ Pharmacol Exp Ther. 1995;275(3):1647-1655.

29. Lonser RR, Sarntinoranont M, Bankiewicz K. Nervous System Drug Delivery: Principles and Practice. Elsevier; 2019.

30. Bankiewicz KS, Sudhakar V, Samaranch L, et al. AAV viral vector delivery to the brain by shape-conforming MR-guided infusions. J Control Release. 2016;240:434-442.

31. Gimenez F, Krauze MT, Valles F, et al. Image-guided convection-enhanced delivery of GDNF protein into monkey putamen. Neuroimage. 2011;54(suppl 1):S189-S195.

32. Chen MY, Lonser RR, Morrison PF, et al. Variables affecting convection-enhanced delivery to the striatum: a systematic examination of rate of infusion, cannula size, infusate concentration, and tissue-cannula sealing time. J Neurosurg. 1999;90(2):315-320.

33. Szerlip NJ, Walbridge S, Yang L, et al. Real-time imaging of convection-enhanced delivery of viruses and virus-sized particles. J Neurosurg. 2007;107(3):560-567.

34. Richardson RM, Kells AP, Rosenbluth KH, et al. Interventional MRI-guided putaminal delivery of AAV2-GDNF for a planned clinical trial in Parkinson's disease. Mol Ther. 2011;19(6):1048-1057.

35. Castle MJ, Perlson E, Holzbaur EL, Wolfe JH. Long-distance axonal transport of AAV9 is driven by dynein and kinesin-2 and is trafficked in a highly motile Rab7-positive compartment. Mol Ther. 2014;22(3):554-566.

36. Krauze MT, Saito R, Noble C, et al. Effects of the perivascular space on convection-enhanced delivery of liposomes in primate putamen. Exp Neurol. 2005;196(1):104-111.

37. Sudhakar V, Naidoo J, Samaranch L, et al. Infuse-as-you-go convective delivery to enhance coverage of elongated brain targets: technical note. J Neurosurg. Published online July 12, 2019. doi:10.3171/2019.4.JNS19826

38. Samaranch L, Salegio EA, San Sebastian W, et al. Strong cortical and spinal cord transduction after AAV7 and AAV9 delivery into the cerebrospinal fluid of nonhuman primates. Hum Gene Ther. 2013;24(5):526-532.

39. Pollock H, Hutchings M, Weller RO, Zhang ET. Perivascular spaces in the basal ganglia of the human brain: their relationship to lacunes. J Anat. 1997;191(Pt 3):337-346.

40. Hadaczek P, Yamashita Y, Mirek H, et al. The "perivascular pump" driven by arterial pulsation is a powerful mechanism for the distribution of therapeutic molecules within the brain. Mol Ther. 2006;14(1):69-78.
41. Richardson RM, Kells AP, Martin AJ, et al. Novel platform for MRI-guided convection-enhanced delivery of therapeutics: preclinical validation in nonhuman primate brain. Stereotact Funct Neurosurg. 2011;89(3):141-151.

42. Heiss JD, Lungu C, Hammoud DA, et al. Trial of magnetic resonance-guided putaminal gene therapy for advanced Parkinson's disease. Mov Disord. 2019;34(7):1073-1078.

43. Chittiboina P, Heiss JD, Warren KE, Lonser RR. Magnetic resonance imaging properties of convective delivery in diffuse intrinsic pontine gliomas. J Neurosurg Pediatr. 2014;13(3):276-282.

44. Kang JH, Chung JK. Molecular-genetic imaging based on reporter gene expression. J Nucl Med. 2008;49(suppl 2):164S179 S.

45. Hadaczek P, Forsayeth J, Mirek H, et al. Transduction of nonhuman primate brain with adeno-associated virus serotype 1: vector trafficking and immune response. Hum Gene Ther. 2009;20(3):225-237.

46. Samaranch L, Hadaczek P, Kells AP, et al. Slow AAV2 clearance from the brain of nonhuman primates and anti-capsid immune response. Gene Ther. 2016;23(4):393-398.

47. Samaranch L, Sebastian WS, Kells AP, et al. AAV9-mediated expression of a non-self protein in nonhuman primate central nervous system triggers widespread neuroinflammation driven by antigen-presenting cell transduction. Mol Ther. 2014;22(2):329-337.

48. Krauze MT, Saito R, Noble C, et al. Reflux-free cannula for convection-enhanced high-speed delivery of therapeutic agents. J Neurosurg. 2005;103(5):923-929.

49. Chittiboina P, Heiss JD, Lonser RR. Accuracy of direct magnetic resonance imaging-guided placement of drug infusion cannulae. J Neurosurg. 2015;122(5):1173-1179.

50. Mohyeldin A, Lonser RR, Elder JB. Real-time magnetic resonance imaging-guided frameless stereotactic brain biopsy: technical note. J Neurosurg. 2016;124(4):1039-1046.

51. Lieberman DM, Laske DW, Morrison PF, et al. Convectionenhanced distribution of large molecules in gray matter during interstitial drug infusion. J Neurosurg. 1995;82(6):10211029.

52. Sudhakar V, Mahmoodi A, Bringas JR, et al. Development of a novel frameless skull-mounted ball-joint guide array for use in image-guided neurosurgery. J Neurosurg. 2020;132(2):595-604.

53. Ahlskog JE, Muenter MD. Frequency of levodopa-related dyskinesias and motor fluctuations as estimated from the cumulative literature. Mov Disord. 2001;16(3):448-458.

54. Voon V, Napier TC, Frank MJ, et al. Impulse control disorders and levodopa-induced dyskinesias in Parkinson's disease: an update. Lancet Neurol. 2017;16(3):238-250.

55. Chan PL, Nutt JG, Holford NH. Pharmacokinetic and pharmacodynamic changes during the first four years of levodopa treatment in Parkinson's disease. J Pharmacokinet Pharmacodyn. 2005;32(3-4):459-484.

56. Ciesielska A, Samaranch L, San Sebastian W, et al. Depletion of AADC activity in caudate nucleus and putamen of Parkinson's disease patients; implications for ongoing AAV2AADC gene therapy trial. PLoS One. 2017;12(2):e0169965.

57. During MJ, Kaplitt MG, Stern MB, Eidelberg D. Subthalamic GAD gene transfer in Parkinson disease patients who are candidates for deep brain stimulation. Hum Gene Ther. 2001;12(12):1589-1591.

58. Kaplitt MG, Feigin A, Tang C, et al. Safety and tolerability of gene therapy with an adeno-associated virus (AAV) borne GAD gene for Parkinson's disease: an open label, phase I trial. Lancet. 2007;369(9579):2097-2105.

59. Niethammer M, Tang CC, LeWitt PA, et al. Long-term follow-up of a randomized AAV2-GAD gene therapy trial for Parkinson's disease. JCI Insight. 2017;2(7):e90133.

60. Niethammer M, Tang CC, Vo A, et al. Gene therapy reduces 
Parkinson's disease symptoms by reorganizing functional brain connectivity. Sci Transl Med. 2018;10(469):eaau0713.

61. Reginensi A, Clarkson M, Neirijnck Y, et al. SOX9 controls epithelial branching by activating RET effector genes during kidney development. Hum Mol Genet. 2011;20(6):1143-1153.

62. Clarkson ED, Zawada WM, Freed CR. GDNF improves survival and reduces apoptosis in human embryonic dopaminergic neurons in vitro. Cell Tissue Res. 1997;289(2):207-210.

63. Clarkson ED, Zawada WM, Freed CR. GDNF reduces apoptosis in dopaminergic neurons in vitro. Neuroreport. 1995; 7(1):145-149.

64. Lin LF, Doherty DH, Lile JD, et al. GDNF: a glial cell linederived neurotrophic factor for midbrain dopaminergic neurons. Science. 1993;260(5111):1130-1132.

65. Gash DM, Zhang Z, Ovadia A, et al. Functional recovery in parkinsonian monkeys treated with GDNF. Nature. 1996;380(6571):252-255.

66. Eslamboli A, Georgievska B, Ridley RM, et al. Continuous low-level glial cell line-derived neurotrophic factor delivery using recombinant adeno-associated viral vectors provides neuroprotection and induces behavioral recovery in a primate model of Parkinson's disease. J Neurosci. 2005;25(4):769777.

67. Kells AP, Eberling J, Su X, et al. Regeneration of the MPTPlesioned dopaminergic system after convection-enhanced delivery of AAV2-GDNF. J Neurosci. 2010;30(28):9567-9577.

68. Johnston LC, Eberling J, Pivirotto P, et al. Clinically relevant effects of convection-enhanced delivery of AAV2-GDNF on the dopaminergic nigrostriatal pathway in aged rhesus monkeys. Hum Gene Ther. 2009;20(5):497-510.

69. Kells AP, Forsayeth J, Bankiewicz KS. Glial-derived neurotrophic factor gene transfer for Parkinson's disease: anterograde distribution of AAV2 vectors in the primate brain. Neurobiol Dis. 2012;48(2):228-235.

70. Brun L, Ngu LH, Keng WT, et al. Clinical and biochemical features of aromatic L-amino acid decarboxylase deficiency. Neurology. 2010;75(1):64-71. Published correction in Neurology. 2010;75(6):576.

71. Hwu WL, Muramatsu S, Tseng SH, et al. Gene therapy for aromatic L-amino acid decarboxylase deficiency. Sci Transl Med. 2012;4(134):134ra61.

72. Chien YH, Lee NC, Tseng SH, et al. Efficacy and safety of
AAV2 gene therapy in children with aromatic L-amino acid decarboxylase deficiency: an open-label, phase 1/2 trial. Lancet Child Adolesc Health. 2017;1(4):265-273.

73. San Sebastian W, Richardson RM, Kells AP, et al. Safety and tolerability of magnetic resonance imaging-guided convection-enhanced delivery of AAV2-hAADC with a novel delivery platform in nonhuman primate striatum. Hum Gene Ther. 2012;23(2):210-217.

74. Lonser RR, Walbridge S, Murray GJ, et al. Convection perfusion of glucocerebrosidase for neuronopathic Gaucher's disease. Ann Neurol. 2005;57(4):542-548.

75. Lonser RR, Schiffman R, Robison RA, et al. Image-guided, direct convective delivery of glucocerebrosidase for neuronopathic Gaucher disease. Neurology. 2007;68(4):254-261.

\section{Disclosures}

Dr. Lonser: direct stock ownership in Brain Neurotherapy Bio, Inc. Dr. Bankiewicz: ownership in Voyager Therapy and Brain Neurotherapy Bio, Inc.

\section{Author Contributions}

Conception and design: Lonser, Elder, Bankiewicz. Acquisition of data: Lonser, Akhter, Bankiewicz. Analysis and interpretation of data: all authors. Drafting the article: Lonser, Zabek, Elder, Bankiewicz. Critically revising the article: all authors. Reviewed submitted version of manuscript: all authors. Approved the final version of the manuscript on behalf of all authors: Lonser. Administrative/technical/material support: Lonser, Bankiewicz. Study supervision: Lonser, Bankiewicz.

\section{Supplemental Information \\ Videos}

Video 1. https://vimeo.com/410980313.

\section{Correspondence}

Russell R. Lonser: The Ohio State University Wexner Medical Center, Ohio State University, Columbus, OH. russell.lonser@ osumc.edu. 